\title{
EFEKTIVITAS LAYANAN INFORMASI MENGGUNAKAN PENDEKATAN ROLE PLAYING UNTUK MENGURANGI AGRESIVITAS SISWA
}

\author{
Rini Hayati ${ }^{1}$, Firman $^{2}$, Sufyarma Marsidin ${ }^{3}$
}

\begin{abstract}
This research was conducted due to the students' high aggressiveness either physically or verbally and either directly or indirectly such as hitting, kicking, speaking harshly, berating, destroying stuffs, and even hurting and harming others. This was an experimental research which used pretest-posttest control group design to see the effectiveness of information service using role playing approach to reduce the students' aggressiveness. The population was students in class VII SMP Negeri 15 Padang. By using random sampling technique, class VII.3 and VII.5 were chosen as the sample.the data of students' aggressiveness were gathered bt using Likert Scale model, The data obtained analyzed by using the Wilcoxon Signed Ranks Test intended to see the difference between the score mean of the students' aggressiveness before and after treatment given to both experimental and control group, and Kolmogorov-Smirnov 2 Independent Samples to see intended to see difference between af the score mean of the students' aggressiveness in the experimentalgroup and in the control group, by using computer program. The findings of this research were: (1) there was a significance difference between the aggressiveness score mean of the student in experimental group before and after information service using role playing approach given, (2) there was difference between the aggressiveness score mean of the student in control group before and after information service without using role playing approach given but it's not significance, and (3) there was a significance difference between the aggressiveness score mean of the students treated by making use of information service using role playing approach and those given information service without using role playing approach. It was concluded that giving information service using role playing approach to the students is effective to reduce their aggressiveness.
\end{abstract}

\section{Keywords: Aggressivenes, Information Services and Role Playing}

\section{PENDAHULUAN}

Pendidikan merupakan upaya strategis untuk mencerdaskan kehidupan bangsa serta meningkatkan harkat dan martabat manusia. Tujuan pendidikan untuk menjadikan peserta didik, memiliki kekuatan spiritual keagamaan, pengendalian diri, kepribadian, kecerdasan, akhlak mulia dan keterampilan. Sekolah merupakan pendidikan yang diselenggarakan secara format, terstruktur dan berjenjang, terdiri dari pendidikan dasar, pendidikan menengah, dan pendidikan tinggi. Bimbingan dan konseling merupakan bagian dari pendidikan yang membantu siswa di sekolah dalam mengentaskan masalah, serta membentuk siswa menjadi pribadi mandiri yang mampu mengendalikan diri. Siswa pada sekolah menengah pertama sedang berada pada masa remaja. Hurlock (1980) menjelaskan perubahan yang terjadi pada masa pubertas yaitu ingin menyendiri, bosan, antagonisme sosial, emosi yang meninggi, suasana hati yang tidak menentu, dan hilangnya kepercayaan diri, karena adanya perubahan hormonal. Hal ini yang menyebabkan banyak terjadinya agresivitas pada masa remaja disebabkan karena suasana hati yang tidak menentu dan emosi yang meninggi. Berkowitz (1995) menjelaskan agresif merupakan segala bentuk perilaku untuk menyakiti seseorang baik secara fisik maupun mental, secara langsung dan tidak langsung. Berdasarkan data yang peneliti peroleh di lapangan tingginya tingkat agresivitas siswa secara fisik maupun verbal. Berikut ini beberapa data agresivitas siswa dalam bentuk fisik yaitu, 20 siswa ikut serta dalam tawuran antara sekolah, 18 siswa berkelahi dengan teman, 4 siswa memukul teman, 11 siswa berlaku kasar kepada teman, 2 siswa mengompas teman, 2 siswa merusak barang milik teman, 11 siswa mengganggu teman, dan agresivitas siswa dalam bentuk verbal yaitu, 12 siswa melawan guru, 9 siswa mengucapkan kata-kata kasar dan memaki kepada teman, 13 siswa mengancam teman. Agresivitas yang terjadi pada siswa dapat terjadi karena kurangnya informasi yang diperoleh siswa tentang menyikapi dan mengelola emosi negatif mereka, seperti dengan pengendalian diri dan berpikir positif tentang perlakuan orang lain terhadap dirinya. Berdasarkan teori pengolahan informasi kognitif sosial yang disampaikan Gannon, Ward, Beech dan Fisher (2007) intervensi dapat dilakukan dengan menggunakan informasi untuk

\footnotetext{
${ }^{1}$ Rini Hayati, Mahasiswa Program Studi S2 Bimbingan dan Konseling, Fakultas Ilmu Pendidikan, UNP

${ }^{2}$ Firman, Dosen Program Studi S2 Bimbingan dan Konseling, Fakultas Ilmu Pendidikan, UNP

${ }^{3}$ Sufyarma Marsidin, Dosen Program Studi S2 Bimbingan dan Konseling, Fakultas Ilmu Pendidikan, UNP
} 
mengurangi atau mencegah perilaku kekerasan. Jika terjadi defisit pemrosesan informasi dalam merespon suatu masalah atau kejadian, hal ini dapat meningkatkan kemungkinan terjadinya perilaku kekerasan. Sekolah sebagai lembaga pendidikan formal memegang peranan dan bertanggung jawab dalam menunjang keberhasilan siswa untuk menjalankan tugastugas perkembangannya dengan baik. Sejalan dengan hal tersebut layanan informasi mempunyai fungsi utama yaitu fungsi pemahaman dan fungsi pencegahan maksudnya bahwa dengan layanan informasi tersebut, individu memiliki pemahaman yang lebih terhadap berbagai hal tentang kehidupan, sehingga dirinya dapat terhindar dari perilaku yang negatif.

Penelitian ini secara umum bertujuan untuk mengetahui efektivitas layanan informasi yang menggunakan pendekatan role playing untuk mengurangi agresivitas siswa. Secara khusus tujuan yang ingin dicapai sebagai berikut: (1) perbedaan skor rata-rata agresivitas siswa kelompok eksperimen sebelum dan sesudah mengikuti layanan informasi yang menggunakan pendekatan role playing, (2) perbedaan skor rata-rata agresivitas siswa kelompok kontrol sebelum dan sesudah mengikuti layanan informasi tanpa pendekatan role playing, (3) perbedaan skor rata-rata agresivitas siswa kelompok eksperimen yang diberikan layanan informasi menggunakan pendekatan role playing dengan siswa kelompok kontrol yang diberikan layanan informasi tanpa pendekatan role playing.

\section{METODOLOGI}

Penelitian ini termasuk penelitian kuantatif metode eksperimen (experiment) dengan desain Pretesst-Posttest Control Group Design, yang bertujuan untuk melihat perbedaan skor rata-rata agresivitas siswa kelompok eksperimen dan kelompok kontrol sebelum dan sesudah diberikan layanan informasi. Populasi penelitian ini adalah siswa SMP Negeri 15 Padang dengan pemilihan sampel dilakukan secara acak, maka diperoleh dua kelas sebagai sampel penelitian yaitu, kelas VII.5 sebagai kelas eksperimen dan kelas VII.3 sebagai kelas kontrol. Uji validitas instrumen penelitian menggunakan Product Moment Correlation dengan taraf signifikansi 0,05 dan uji reliabilitas menggunakan rumus Alpha Cronbach. Tingkat reliabilitas instrumen penelitian 0,923.

Instrumen yang digunakan pada penelitian ini berupa model skala Likert. Data yang telah terkumpul akan dianalisis dengan cara menghitung skor rata-rata agresivitas siswa, Kemudian deskripsikan data tentang agresivitas siswa, norma kategori diklasifikasikan dengan kriteria yaitu:

Tabel 1. Penetapan Kategori Agresivitas

\begin{tabular}{|c|c|}
\hline Skor & Kategori \\
\hline $\mathrm{X} \leq 84$ & Sangat Rendah \\
$84<\mathrm{X} \leq 112$ & Rendah \\
$112<\mathrm{X} \leq 140$ & Sedang \\
$140<\mathrm{X} \leq 168$ & Tinggi \\
$168<\mathrm{X}$ & Sangat Tinggi \\
\hline
\end{tabular}

Berdasarkan Tabel 1 tersebut dapat dimaknai bahwa semakin rendah skor agresivitas yang diperoleh siswa maka semakin rendah tingkat agresivitas siswa. sebaliknya semakin tinggi skor agresivitas yang diperoleh siswa, menggambarkan semakin tinggi tingkat agresivitas siswa. Selanjutnya data yang diperoleh dianalisis dengan menggunakan uji Wilcoxon Signed Ranks Test dan KolmogorovSmirnov 2 Independent Samples.

\section{HASIL DAN PEMBAHASAN}

\section{A. Hasil}

\section{Perbedaan Skor Agresivitas Siswa Kelompok Eksperimen Sebelum dan Sesudah Perlakuan}

Kondisi agresivitas siswa pada kelompok eksperimen sebelum dan sesudah diberikan perlakuan layanan informasi yang menggunakan pendekatan role playing, dapat dilihat pada diagram dibawah ini.

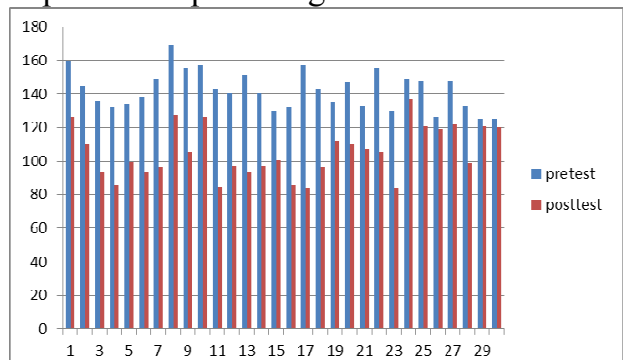

Gambar 1. Diagram Hasil Pretest Dan Posttest Kelompok Eksperimen

Data hasil penelitian menunjukan perbedaan skor agresivitas siswa pada kelompok eksperimen yang diberikan layanan informasi menggunakan pendekatan role playing dapat mengurangi skor rata-rata tingkat agresivitas siswa yang signifikan. Berdasarkan data hasil pretest dan posttest yang menggunakan uji Wilcoxon Signed Ranks Test menunjukan bahwa hasil probabilitas Sig. (2-tailed) agresivitas siswa kelompok eksperimen sebesar 0,000 atau probabilitas di bawah alpha 0,05 $(0,000<0,05)$ maka terdapat perbedaan skor 
yang signifikan agresivitas siswa kelompok eksperimen sebelum dan sesudah diberi perlakuan layanan informasi yang menggunaka pendekatan role playing. Hasil rata-rata skor kelompok eksperimen pada pretest 142,2 menjadi 105,3 pada posttest berkurang sebanyak 36,9 skor.

\section{Perbedaan Skor Agresivitas Siswa Kelompok Kontrol Sebelum dan Sesudah Perlakuan}

Kondisi agresivitas siswa pada kelompok kontrol sebelum dan sesudah diberikan layanan informasi tanpa pendekatan role playing dapat dilihat pada diagram berikut:

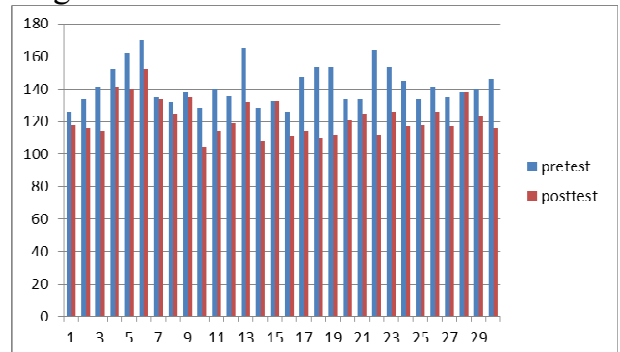

Gambar 2. Diagram Hasil Pretest Dan Posttest Kelompok Kontrol

Data hasil penelitian pada kelompok kontrol menunjukkan perbedaan perolehan skor agresivitas siswa pada pretest dan posttest kelompok kontrol tidak terlalu besar. Berdasarkan data hasil pretest dan posttest yang menggunakan uji Wilcoxon Signed Ranks Test menunjukan bahwa hasil probabilitas Sig. (2-tailed) agresivitas siswa kelompok kontrol sebesar 0,000 atau probabilitas di bawah alpha 0,05 $(0,000<0,05)$ maka terdapat perbedaan skor agresivitas siswa kelompok kontrol yang diberikan layanan informasi tanpa pendekatan. Pada pretest skor rata-rata kelompok kontrol 142,1 nmenjadi 122,4 pada posttest, terlihat penurunan yang sangat lambat dimana siswa hanya mampu menurunkan agresivitas siswa sebanyak 16,1 skor.

\section{Perbedaan Agresivitas Siswa Kelompok Eksperimen dan Kelompok Kontrol}

Perbedaan agresivitas siswa kelompok eksperimen dan kelompok kontrol yang signifikat dapat dilihat dari skor rata-rata berdasarkan hasil pretest dan posttest data hasil penelitian dapat dilihat pada berikut:

Tabel 2. Hasil Pretest dan Posttest Kelompok Eksperimen dan Kelompok Kontrol.

\begin{tabular}{|l|c|c|c|}
\hline \multicolumn{2}{|c|}{ Sampel } & \multicolumn{2}{c|}{ Mean Rank } \\
\hline Kelompok & N & Pretest & Posttest \\
\hline \hline Eksperimen & 30 & 142,2 & 105,3 \\
\hline Kontrol & 30 & 142,1 & 122,4 \\
\hline \multicolumn{2}{|c|}{ Hasil penelitian menunjukkan }
\end{tabular}

perbedaan yang signifikan agresivitas siswa kelompok eksperimen yang diberikan layanan informasi yang menggunakan pendekatan role playing, dengan kelompok kontrol yang diberikan layanan informasi biasa (tanpa pendekatan). Berdasarkan data hasil pretest dan posttest yang menggunakan uji Kolmogorov-Smirnov 2 Independent Samples terhadap kelompok eksperimen dan kelompok kontrol menunjukan bahwa hasil probabilitas Sig. (2-Tailed) agresivitas siswa kelompok eksperimen dan kelompok kontrol sebesar 0,000 atau probabilitas di bawah alpha $0,05 \quad(0,000<0,05)$ maka terdapat perbedaan skor agresivitas siswa kelompok eksperimen dengan kelompok kontrol. Hasil posttest kelompok eksperimen 105,3 dan posttest kelompok kontrol 122,4. Dari hal ini dapat dilihat perbedaan sebesar 17,1 skor antara posttest kelompok eksperimen dan posttest kelompok kontrol.

Berdasarkan analisis hasil penelitian terlihat bahwa terdapat perbedaan skor ratarata yang signifikan pada pretest dan posttest antara agresivitas siswa kelompok eksperimen yang diberikan layanan informasi menggunakan pendekatan role playing dan kelompok kontrol yang diberikan layanan informasi tanpa pendekatan, perbedaan dapat di lihat pada diagram di bawah ini.

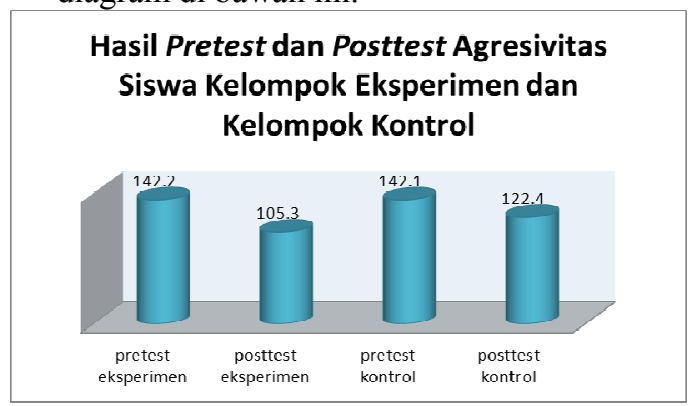

\section{B. Pembahasan}

Berdasarkan hasil penelitian yang telah diuraikan, maka terdapat perbedaan yang signifikan antara agresivitas siswa kelompok eksperimen dan kelompok kontrol. Pada bagian berikut akan dijelaskan pembahasan 
untuk masing-masing variabel yang dikaji dalam penelitian.

\section{Perbedaan Skor Agresivitas Siswa pada Kelompok Eksperimen (Pretest dan Posttest)}

Agresivitas siswa pada kelompok eksperimen sebelum diberi perlakukan berada pada kategori tinggi, dan sesudah diberi perlakuan layanan informasi menggunakan role playing berkurang menjadi berada pada kategori rendah, hal ini menunjukan bahwa layanan informasi menggunakan role playing efektif untuk mengurangi agresivitas siswa. Berdasarkan hasil pengujian hipotesis pertama yang berbunyi "Terdapat perbedaan yang signifikan pada agresivitas siswa kelompok eksperimen sebelum dan sesudah diberikan perlakuan berupa pemberian layanan informasi yang menggunakan pendekatan role playing".

Berkaitan dengan hal itu Sarwono dan Meinarno (2011) menjelaskan salah satu cara mengatasi agresivitas yaitu dengan kognitif, ketika seseorang berbuat kesalahan pada orang lain maka orang yang dizalimi akan marah. Namun jika ternyata orang yang dizalimi ternyata memaafkan, hal ini menjadi mungkin ketika kognisi orang yang dizalimi tadi diisi dengan informasi bahwa perlu memaafkan dengan tulus dan ikhlas orang yang dizalimi. Hal ini bisa mengurangi agresivitas yang tampak.

Uno (2007:25) menjelaskan model pembelajaran bermain peran (role playing) dapat mendorong siswa mengekspresikan perasaan dan melepaskannya dengan melibatkan sikap, nilai dan keyakinan yang mengarah pada kesadaran melalui keterlibatan spontan yang disertai analisis. Berdasarkan penjelasan di atas, menunjukan bahwa model pendekatan role playing dapat dilakukan agar siswa memahami diri dan orang lain serta mampu menempatkan diri dalam posisi dan situasi orang yang mengalaminya. Berdasarkan penjelasan di atas dapat dipahami bahwa perlu adanya suatu upaya untuk melaksanakan layanan informasi dengan model dan materi khusus untuk mengurangi agresivitas siswa, sehingga siswa tidak hanya mendapatkan pengetahuan dan pemahaman dari layanan informasi yang diberikan, siswa mendapat pengetahuan tentang pengaturan diri yang baik, siswa juga dapat membuat pilihan untuk masa depan.

\section{Perbedaan Skor Rata-rata Agresivitas Siswa pada Kelompok Kontrol (Pretest dan Posttest)}

Agresivitas siswa pada kelompok kontrol sebelum diberi perlakukan berada pada kategori tinggi dan sesudah diberi perlakukan layanan informasi tanpa pendekatan hanya mampu berkurang pada kategori sedang. Hal ini menunjukan bahwa upaya yang dilakukan untuk mengurangi agresivitas siswa dapat juga dilakukan dengan layanan informasi yang konvensional. Seperti yang dilakukan pada kelompok kontrol. Setelah diberikan layanan layanan informasi tanpa menggunakan pendekatan role playing terdapat perbedaan antara agresivitas siswa kelompok kontrol pada rata-rata skor pretest dan posttest, namun perbedaan tersebut tidak signifikan. Pelaksanaan layanan informasi dalam penelitian ini adalah untuk mengurangi agresivitas siswa.

Pada pelaksanaan layanan informasi siswa diberikan berbagai materi terkait dengan agresivitas melalui pemberian informasi dengan cara menjelaskan dan ceramah. Agresivitas yang diharapkan melalui layanan informasi adalah diperolehnya pengetahuan dan pemahaman tentang cara berperilaku dan merespon perilaku agresif orang lain. Dalam penelitian ini kelompok kontrol hanya diberikan layanan informasi ceramah biasa, sehingga tidak banyak melibatkan keefektifan siswa dalam mengembangkan pikiran, wawasan maupun pengetahuan seperti halnya pada kegiatan layanan informasi dengan menggunakan pendekatan role playing.

\section{Perbedaan Agresivitas Siswa Kelompok Eksperimen dan Kelompok Kontrol}

Hasil penelitian menunjukkan terdapat perbedaan yang signifikan agresivitas siswa kelompok eksperimen yang diberikan layanan informasi yang menggunakan pendekatan role playing, dengan kelompok kontrol yang diberikan layanan informasi biasa (tanpa pendekatan). Penyampaian informasi dapat dilakukan dengan berbagai model pendekatan yang dapat menunjang pelaksanaan layanan informasi untuk tercapainya tujuan pelayanan. Penggunaan model pendekatan harus mempertimbangkan segi efektivitas dan efisiensinya. Menurut Joyce dan Weil (1992) Model pengajaran bermain peran baik dalam dimensi personal, sosial dan pendidikan. Model ini mencoba untuk membantu individu menemukan 
makna pribadi dalam dunia sosial mereka, dan menyelesaikan dilema pribadi dengan bantuan dari kelompok sosial. Pada dimensi sosial, memungkinkan individu untuk bekerja sama menganalisis situasi sosial, terutama masalah interpersonal, mengembangkan cara-cara yang layak dan demokratis untuk mengatasi masalah situasional.

Hasil analisis data mengungkapkan bahwa layanan informasi dengan menggunakan pendekatan role playing efektif untuk mengurangi agresivitas siswa. Keefektifan ini terlibat dari jumlah keseluruhan analisis yang dilakukan di mana skor hasil agresivitas siswa kelompok eksperimen mengalami penurunan yang signifikan dibandingkan kelompok kontrol. Hasil penelitian menunjukkan bahwa pada saat pretest kondisi agresivitas siswa kelompok eksperimen dan kelompok kontrol berada pada kategori tinggi. Setelah diberikan perlakuan yaitu layanan informasi yang menggunakan pendekatan role playing pada kelompok eksperimen skor rata-rata agresivitas siswa mengalami penurunan. Sedangkan kelompok kontrol dengan menggunakan layanan informasi biasa, agresivitas pada siswa juga mengalami penurunan, akan tetapi penurunan yang terjadi pada kelompok kontrol tidak terlalu signifikan dibandingkan kelompok eksperimen.

Berdasarkan teori pengolahan informasi kognitif sosial yang disampaikan Gannon, Ward, Beech dan Fisher (2007) intervensi dapat dilakukan dengan menggunakan informasi untuk mengurangi atau mencegah perilaku kekerasan. Jika terjadi defisit pemrosesan informasi hal ini dapat meningkatkan kemungkinan terjadinya perilaku kekerasan.

Skor rata-rata agresivitas siswa menurun setelah diberikan layanan informasi yang menggunakan pendekatan role playing pada kelompok eksperimen. Hal ini menunjukkan bahwa layanan informasi yang menggunakan role playing efektif digunakan untuk mengurangi agresivitas siswa. Sesuai dengan pendapat Phillips, Harsey dan Kanagy (dalam Erford, 2004) menjelaskan tentang mengajarkan siswa sekolah menengah untuk menangani kemarahan dengan cara yang positif yaitu dengan mengajak mereka untuk memerankan kemarahannya, kemudian memikirkan konsekuensi dari tindakannya tersebut, selanjutnya konselor mengajak mereka untuk membahas reaksi dari peran yang dimainkan dan melakukan evaluasi, kemudian dilakukan penguatan positif untuk perilaku yang sesuai dan hukuman bagi perilaku yang tidak sesuai, hal ini akan membantu siswa untuk menghilangkan perilaku agresif.

Dari uraian di atas, dapat diketahui pentingnya suatu model pendekatan yang dilakukan pada proses pelayanan yang menyenangkan yang membuat suasana kelas tidak monoton. Bimbingan dan Konseling akan menjadi positif dikarenakan gurunya menguasai materi dengan model pendekatan yang menyenangkan. Siswa akan mulai merasakan fungsi BK setelah pelayanan bermakna ini. Siswa mempunyai kesan yang mendalam atas kegiatan yang terjadi di kelas.

\section{KESIMPULAN DAN SARAN \\ A. Kesimpulan}

Berdasarkan temuan dan analisis hasil penelitian mengenai agresivitas siswa dapat disimpulkan sebagai berikut:

1. Terdapat penurunan skor rata-rata agresivitas siswa pada kelompok eksperimen yang diberikan layanan informasi yang menggunakan pendekatan role playing sebelum perlakuan yang berada pada kategori tinggi dan sesudah diberi perlakuan berada pada kategori rendah.

2. Terdapat penurunan skor rata-rata agresivitas siswa pada kelompok kontrol yang diberikan layanan informasi tanpa menggunakan pendekatan pada pretest dan posttest, namun penurunan tersebut dari kategori tinggi sebelum diberi perlakuan ke kategori sedang sesudah diberi perlakuan.

3. Terdapat perbedaan skor rata-rata agresivitas siswa kelompok eksperimen diberikan layanan informasi yang menggunakan pendekatan role playing dengan siswa kelompok kontrol yang diberikan layanan informasi tanpa pendekatan role playing. Pada kelompok eksperimen penurunan skor rata-rata dari kategori tinggi ke kategori rendah, pada kelompok kontrol dari kategori tinggi ke kategori sedang. Hal ini menunjukan layanan informasi yang menggunakan role playing efektif digunakan untuk mengurangi agresivitas siswa.

\section{B. Saran}

Berdasarkan hasil penelitian maka dapat diajukan beberapa saran sebagai tindak lanjut penelitian ini yaitu: 
1. Bagi Guru BK/Konselor

Guru BK/konselor dapat membuat program secara terjadwal sehingga dapat mencegah serta mengurangi terjadinya agresivitas siswa.

2. MGBK

Kepada Musyawarah Guru Bimbingan dan Konseling (MGBK) hendaknya dalam upaya meningkatkan keprofesionalan guru $\mathrm{BK} /$ Konselor sekolah yaitu dengan mengadakan kegiatan workshop terkait dengan pelaksanaan layanan informasi yang menggunakan pendekatan role playing.

3. Kepala Sekolah

Kepala sekolah memberi kesempatan pada guru $\mathrm{BK} /$ konselor untuk aktif mengikuti pelatihan-pelatihan yang bermanfaat dalam meningkatkan kemampuan penyelenggaraan layanan.

4. Bagi Jurusan Bimbingan dan Konseling Sebagai bahan untuk dapat menghasilkan mahasiswa dan alumni Bimbingan dan Konseling yang profesional dalam melaksanakan praktek di lapangan khususnya praktek layanan Informasi yang menggunakan pendekatan role playing untuk mengurangi agresivitaas siswa, dan pendekatan lain yang lebih menarik.

5. Bagi LPMP

Kepada LPMP agar melaksanakan pelatihan kepada guru $\mathrm{BK} /$ konselor agar dapat melaksanakan layanan informasi dengan pendekatan role playing untuk mengurangi agresivitas siswa.

6. Bagi Kepala Dinas

Kepala Dinas Pendidikan agar memetakan guru untuk diberi pelatihan kepada guru BK/konselor dalam memberikan layanan informasi dengan pendekatan role playing untuk mengurangi agresivitas siswa.

7. Bagi Kepolisian

Kepolisian hendaknya dapat bekerjasama dengan guru $\mathrm{BK} /$ Konselor sekolah untuk memberi pembinaan dan pencegahan terjadinya agresivitas siswa seperti tawuran.

8. Bagi peneliti

Bagi peneliti perlu adanya penelitian lebih lanjut berkenaan dengan pelaksanaan layanan informasi yang menggunakan pendekatan role playing untuk mengurangi agresivitas siswa.

\section{DAFTAR RUJUKAN}

Berkowitz, L. 1995. Aggression Its Causes, Cosequences and Control Terjemahan oleh Susiatni Hartatni Woro: Agresi 1 sebab dan akibatnya Jakarta: Pustaka Binama Pressindo.

Erford, B. T. 2004. Professional School Counseling: A handbook of theories, programs and practices. USA: Pro-Ed. Inc.

Gannon, T. A., Ward, T., Beech A. R., dan Fisher, D. 2007. Aggressive Offenders Cognition Theory, Research, and Practice. England: John Willey \& Sons.

Hurlock, E. B. 1980. Psikologi Perkembangan Suatu Pendekatan Sepanjang Rentang Kehidupan. Terjemahan oleh Istiwidayanti. Jakarta: Erlangga.

Joyce, B., dan Weil, M. 1992. Models of Teaching. USA: Allyn and Bacon.

Sarwono, Sarlito W dan Meinarno, Eko A. 2011. Psikologi Sosial. Jakarta: Salemba Humanika.

Uno, Hamzah B. 2011. Model Pembelajaran: Menciptakan proses belajar mengajar yang kreatif dan efektif. Jakarta: Bumi Aksara. 